\title{
Fixed point results in generalized metric spaces without Hausdorff property
}

\author{
Z. Kadelburg $\cdot$ S. Radenović
}

Received: 11 December 2013/Accepted: 3 July 2014/Published online: 27 August 2014

(C) The Author(s) 2014. This article is published with open access at Springerlink.com

\begin{abstract}
It is well known that generalized metric spaces in the sense of Branciari might not be Hausdorff and, hence, there may exist sequences in them having more than one limit. Thus, in most of the fixed point results obtained recently in such spaces, Hausdorffness was additionally assumed. We show in this article that, nevertheless, most of these results remain valid without this additional assumption.
\end{abstract}

Keywords Generalized metric space $\cdot$ Rectangular space $\cdot$ Geraghty condition $\cdot$ Altering distance $\cdot$ Cone metric space

\section{Mathematics Subject Classification (2010) $47 \mathrm{H} 10$. $54 \mathrm{H} 25$}

\section{Introduction}

A lot of generalizations of metric spaces exist. Most of them were introduced in an attempt to extend some fixed point theorems known from the metric case. One of the fruitful generalizations of this kind was given by Branciari in 2000 [1] who replaced the triangular inequality by a more general one, which was later usually called a rectangular or a quadrilateral inequality. These new spaces became known as generalized metric spaces (g.m.s., for

\section{Z. Kadelburg ( $\square)$}

Faculty of Mathematics, University of Belgrade, Beograd, Serbia

e-mail: kadelbur@matf.bg.ac.rs

\section{S. Radenović}

Faculty of Mechanical Engineering, University of Belgrade,

Kraljice Marije 16, 11120 Beograd, Serbia

e-mail: radens@beotel.net short) or rectangular spaces. Several authors (e.g., [2-29]) proved various (common) fixed point results is such spaces.

In some of the first papers which dealt with fixed point theorems in g.m.s., it was sometimes implicitly assumed that the respective topology is Hausdorff and/or that the generalized metric is continuous (see, e.g., $[1,5,11,19]$ ). However, as shown by examples in [26, 27], a generalized metric need not be continuous, neither the respective topology need to be Hausdorff. Hence, in further articles, usually one or both of these conditions were additionally assumed (see, e.g., [4, 7-10, 12, 14, 19, 20, 25, 27]).

In this paper, we show that a number of these results are nevertheless valid without assumptions of generalized metric being continuous or the respective topology being Hausdorff. In particular, we prove (common) fixed point results that are extensions of Geraghty-type results, results using altering distance or admissible functions and results in generalized cone metric spaces. References to some further results can be found in [30].

\section{Preliminaries and auxiliary results}

The following definition was given by Branciari in [1].

Definition 1 Let $X$ be a nonempty set, and let $d$ : $X \times X \rightarrow[0,+\infty)$ be a mapping such that for all $x, y \in X$ and all distinct points $u, v \in X$, each distinct from $x$ and $y$ :

1. $d(x, y)=0$ iff $x=y$;

2. $\quad d(x, y)=d(y, x)$

3. $d(x, y) \leq d(x, u)+d(u, v)+d(v, y) \quad$ (rectangular inequality).

Then $(X, d)$ is called a generalized metric space (g.m.s.).

Convergent and Cauchy sequences in g.m.s., completeness, as well as open balls $B_{r}(p)$, can be introduced in a 
standard way. However, the following example, presented by Sarma et al. in [27, Example 1.1] (see also [26]), shows several possible properties of generalized metrics, different than in the standard metric case.

Example 1 [27] Let $A=\{0,2\}, \quad B=\left\{\frac{1}{n}: n \in \mathbb{N}\right\}$, $X=A \cup B$. Define $d: X \times X \rightarrow[0,+\infty)$ as follows:

$$
d(x, y)= \begin{cases}0, & x=y \\ 1, & x \neq y \text { and }\{\mathrm{x}, \mathrm{y}\} \subset \mathrm{A} \text { or }\{\mathrm{x}, \mathrm{y}\} \subset \mathrm{B} \\ y, & x \in A, y \in B \\ x, & x \in B, y \in A .\end{cases}
$$

Then $(X, d)$ is a complete g.m.s. However, it was shown in [27, Example 1.1] that:

- there exists a convergent sequence in $(X, d)$ which is not a Cauchy sequence;

- there exists a sequence in $(X, d)$ converging to two distinct points;

- there is no $r>0$ such that $B_{r}(0) \cap B_{r}(2)=\emptyset$;

- $\lim _{n \rightarrow \infty} \frac{1}{n}=0$ but $\lim _{n \rightarrow \infty} d\left(\frac{1}{n}, \frac{1}{2}\right) \neq d\left(0, \frac{1}{2}\right)$; hence $d$ is not a continuous function.

As shown in the previous example, a sequence in a g.m.s. may have two limits. However, there is a special situation where this is not possible, and this will be useful in some proofs. The following lemma is a variant of [31, Lemma 1.10].

Lemma 1 Let $(X, d)$ be a g.m.s. and let $\left\{x_{n}\right\}$ be a Cauchy sequence in $X$ such that $x_{m} \neq x_{n}$ whenever $m \neq n$. Then $\left\{x_{n}\right\}$ can converge to at most one point.

Proof Suppose, to the contrary, that $\lim _{n \rightarrow \infty} x_{n}=x$, $\lim _{n \rightarrow \infty} x_{n}=y$ and $x \neq y$. Since $x_{m}$ and $x_{n}$ are distinct elements, as well as $x$ and $y$, it is clear that there exists $\ell \in \mathbb{N}$ such that $x$ and $y$ are different from $x_{n}$ for all $n>l$. For $m, n>\ell$, the rectangular inequality implies that

$d(x, y) \leq d\left(x, x_{m}\right)+d\left(x_{m}, x_{n}\right)+d\left(x_{n}, y\right)$.

Taking the limit as $m, n \rightarrow \infty$, it follows that $d(x, y)=0$, i.e., $x=y$. Contradiction.

The following lemma is a g.m.s. modification of a result which is well-known in metric spaces (see, e,g,. [32, Lemma 2.1]). Using it, many known proofs of fixed point results in g.m. spaces become much shorter.

Lemma 2 Let $(X, d)$ be a g.m.s. and let $\left\{y_{n}\right\}$ be a sequence in $X$ with distinct elements $\left(y_{n} \neq y_{m}\right.$ for $\left.n \neq m\right)$. Suppose that $d\left(y_{n}, y_{n+1}\right)$ and $d\left(y_{n}, y_{n+2}\right)$ tend to 0 as $n \rightarrow \infty$ and that $\left\{y_{n}\right\}$ is not a Cauchy sequence. Then there exist $\varepsilon>0$ and two sequences $\left\{m_{k}\right\}$ and $\left\{n_{k}\right\}$ of positive integers such that $n_{k}>m_{k}>k$ and the following four sequences tend to $\varepsilon$ as $k \rightarrow \infty$ : $d\left(y_{m_{k}}, y_{n_{k}}\right), \quad d\left(y_{m_{k}}, y_{n_{k}+1}\right), \quad d\left(y_{m_{k}-1}, y_{n_{k}}\right), \quad d\left(y_{m_{k}-1}, y_{n_{k}+1}\right)$.

Proof Since $\left\{y_{n}\right\}$ is not a Cauchy sequence, there exist $\varepsilon>0$ and two sequences $\left\{m_{k}\right\}$ and $\left\{n_{k}\right\}$ of positive integers such that $n_{k}>m_{k}>k, d\left(y_{m_{k}}, y_{n_{k}}\right) \geq \varepsilon$ and $n_{k}$ is the smallest integer satisfying this inequality, i.e., $d\left(y_{m_{k}}, y_{\ell}\right)<\varepsilon$ for $m_{k}<\ell<n_{k}$.

Let us prove that the first of the sequences in (2.1) tends to $\varepsilon$ as $k \rightarrow \infty$. Note that, by the assumption, $d\left(y_{m_{k}}, y_{m_{k}+1}\right) \rightarrow 0 \quad$ and $\quad d\left(y_{m_{k}}, y_{m_{k}+2}\right) \rightarrow 0 \quad$ as $\quad k \rightarrow \infty$. Hence, it is impossible that $n_{k}=m_{k}+1$ or $n_{k}=m_{k}+2$ (because in either of these cases it would be impossible to have $d\left(y_{m_{k}}, y_{n_{k}}\right) \geq \varepsilon$ ). Thus, we can apply the rectangular inequality to obtain

$$
\begin{aligned}
\varepsilon & \leq d\left(y_{m_{k}}, y_{n_{k}}\right) \leq d\left(y_{m_{k}}, y_{n_{k}-2}\right)+d\left(y_{n_{k}-2}, y_{n_{k}-1}\right)+d\left(y_{n_{k}-1}, y_{n_{k}}\right) \\
& \leq \varepsilon+d\left(y_{n_{k}-2}, y_{n_{k}-1}\right)+d\left(y_{n_{k}-1}, y_{n_{k}}\right) \rightarrow \varepsilon,
\end{aligned}
$$

as $k \rightarrow \infty$, implying that $d\left(y_{m_{k}}, y_{n_{k}}\right) \rightarrow \varepsilon$ as $k \rightarrow \infty$.

In order to prove that the second sequence in (2.1) tends to $\varepsilon$ as $k \rightarrow \infty$, consider the following two rectangular inequalities:

$$
\begin{aligned}
d\left(y_{m_{k}}, y_{n_{k}+1}\right) & \leq d\left(y_{m_{k}}, y_{n_{k}}\right)+d\left(y_{n_{k}}, y_{n_{k}-1}\right)+d\left(y_{n_{k}-1}, y_{n_{k}+1}\right) \\
d\left(y_{m_{k}}, y_{n_{k}}\right) & \leq d\left(y_{m_{k}}, y_{n_{k}+1}\right)+d\left(y_{n_{k}+1}, y_{n_{k}-1}\right)+d\left(y_{n_{k}-1}, y_{n_{k}}\right),
\end{aligned}
$$

which, together with $d\left(y_{m_{k}}, y_{n_{k}}\right) \rightarrow \varepsilon$ imply that $d\left(y_{m_{k}}, y_{n_{k}+1}\right) \rightarrow \varepsilon$ as $k \rightarrow \infty$.

The proof for the other two sequences can be done in a similar way, using the following rectangles:

$$
\left(y_{m_{k}-1}, y_{n_{k}}, y_{n_{k}-2}, y_{m_{k}}\right) \text { and }\left(\mathrm{y}_{\mathrm{m}_{\mathrm{k}}}, \mathrm{y}_{\mathrm{n}_{\mathrm{k}}}, \mathrm{y}_{\mathrm{m}_{\mathrm{k}}-1}, \mathrm{y}_{\mathrm{m}_{\mathrm{k}}-2}\right) \text {, }
$$

resp.

$$
\left(y_{m_{k}-1}, y_{n_{k}+1}, y_{n_{k}}, y_{m_{k}}\right) \quad \text { and } \quad\left(\mathrm{y}_{\mathrm{m}_{\mathrm{k}}}, \mathrm{y}_{\mathrm{n}_{\mathrm{k}}}, \mathrm{y}_{\mathrm{m}_{\mathrm{k}}+1}, \mathrm{y}_{\mathrm{n}_{\mathrm{k}}-1}\right) .
$$

\section{Main results}

Geraghty-type conditions

In the following Geraghty-type result [33], we will use the class $\mathcal{S}$ of real functions $\beta:[0,+\infty) \rightarrow[0,1)$ satisfying the condition

$\beta\left(t_{n}\right) \rightarrow 1$ as $n \rightarrow \infty$ implies $t_{n} \rightarrow 0$ as $n \rightarrow \infty$.

Note that we neither assume that the space $(X, d)$ is Hausdorff, nor that the mapping $d$ is continuous.

Theorem 1 Let $(X, d)$ be a g.m.s. and let $f, g: X \rightarrow X$ be two self maps such that $f(X) \subseteq g(X)$, one of these two subsets of $X$ being complete. If, for some function $\beta \in \mathcal{S}$, 


$$
d(f x, f y) \leq \beta(d(g x, g y)) d(g x, g y)
$$

holds for all $x, y \in X$, then $f$ and $g$ have a unique point of coincidence $y^{*}$. Moreover, for each $x_{0} \in X$, a corresponding Jungck sequence $\left\{y_{n}\right\}$ can be chosen such that $\lim _{n \rightarrow \infty} y_{n}=y^{*}$.

If, moreover, $f$ and $g$ are weakly compatible, then they have a unique common fixed point.

Proof We will prove first that $f$ and $g$ cannot have more than one point of coincidence. Suppose to the contrary that there exist $w_{1}, w_{2} \in X$ such that $w_{1} \neq w_{2}, w_{1}=f u_{1}=g u_{1}$ and $w_{2}=f u_{2}=g u_{2}$ for some $u_{1}, u_{2} \in X$. Then (3.1) would imply that

$$
\begin{aligned}
d\left(w_{1}, w_{2}\right) & =d\left(f u_{1}, f u_{2}\right) \leq \beta\left(d\left(g u_{1}, g u_{2}\right)\right) d\left(g u_{1}, g u_{2}\right) \\
& =\beta\left(d\left(w_{1}, w_{2}\right)\right) d\left(w_{1}, w_{2}\right)<d\left(w_{1}, w_{2}\right),
\end{aligned}
$$

which is impossible.

In order to prove that $f$ and $g$ have a coincidence point, take an arbitrary $x_{0} \in X$ and, using that $f(X) \subseteq g(X)$, choose sequences $\left\{x_{n}\right\}$ and $\left\{y_{n}\right\}$ in $X$ such that

$y_{n}=f x_{n}=g x_{n+1}, \quad$ for $n=0,1,2, \ldots$

Moreover, if $y_{n}=y_{m}$ for some $n \neq m$, then we choose $x_{n+1}=x_{m+1}\left(\right.$ and hence also $\left.y_{n+1}=y_{m+1}\right)$.

If $y_{n_{0}}=y_{n_{0}+1}$ for some $n_{0} \in \mathbb{N}$, then $x_{n_{0}+1}$ is a coincidence point of $f$ and $g$, and $y_{n_{0}+1}$ is their (unique) point of coincidence.

Suppose now that $y_{n} \neq y_{n+1}$ for each $n \in \mathbb{N}$. Then, using (3.1), we get that

$$
\begin{aligned}
d\left(y_{n}, y_{n+1}\right) & =d\left(f x_{n}, f x_{n+1}\right) \leq \beta\left(d\left(g x_{n}, g x_{n+1}\right)\right) d\left(g x_{n}, g x_{n+1}\right) \\
& =\beta\left(d\left(y_{n-1}, y_{n}\right)\right) d\left(y_{n-1}, y_{n}\right)<d\left(y_{n-1}, y_{n}\right) .
\end{aligned}
$$

Hence, $\left\{d\left(y_{n}, y_{n+1}\right)\right\}$ is a strictly decreasing sequence of positive real numbers, tending to some $\delta \geq 0$. Suppose that $\delta>0$. Then, since

$$
\frac{d\left(y_{n}, y_{n+1}\right)}{d\left(y_{n-1}, y_{n}\right)} \leq \beta\left(d\left(y_{n-1}, y_{n}\right)\right)<1,
$$

taking the limit as $n \rightarrow \infty$, we get that $\beta\left(d\left(y_{n-1}, y_{n}\right)\right) \rightarrow 1$. But this implies that $d\left(y_{n-1}, y_{n}\right) \rightarrow 0$, a contradiction. Hence,

$$
d\left(y_{n-1}, y_{n}\right) \rightarrow 0 \text { as } n \rightarrow \infty .
$$

In a similar way, one can prove that

$$
d\left(y_{n-2}, y_{n}\right) \rightarrow 0 \text { as } n \rightarrow \infty .
$$

Suppose now that $y_{n}=y_{m}$ for some $n>m$ (and hence, by the way $y_{n}$ 's are chosen, $y_{n+k}=y_{m+k}$ for $\left.k \in \mathbb{N}\right)$. Then, (3.1) implies that $d\left(y_{m}, y_{m+1}\right)=d\left(y_{n}, y_{n+1}\right) \leq \beta\left(d\left(y_{n-1}, y_{n}\right)\right) d\left(y_{n-1}, y_{n}\right) \leq \cdots$

$\leq \beta\left(d\left(y_{n-1}, y_{n}\right)\right) \cdots \beta\left(d\left(y_{m}, y_{m+1}\right)\right) d\left(y_{m}, y_{m+1}\right)<d\left(y_{m}, y_{m+1}\right)$,

a contradiction. Thus, in what follows, we can assume that $y_{n} \neq y_{m}$ for $n \neq m$.

In order to prove that $\left\{y_{n}\right\}$ is a Cauchy sequence, suppose that it is not. Then, by Lemma 2, using (3.2) and (3.3), we conclude that there exist $\varepsilon>0$ and two sequences $\left\{m_{k}\right\}$ and $\left\{n_{k}\right\}$ of positive integers such that $n_{k}>m_{k}>k$ and the sequences (2.1) tend to $\varepsilon$ as $k \rightarrow \infty$. Using (3.1) with $x=x_{m_{k}}$ and $y=x_{n_{k}+1}$, one obtains $\frac{d\left(y_{m_{k}}, y_{n_{k}+1}\right)}{d\left(y_{m_{k}-1}, y_{n_{k}}\right)} \leq \beta\left(d\left(y_{m_{k}-1}, y_{n_{k}}\right)\right)<1$.

Letting $k \rightarrow \infty$, it follows that $\beta\left(d\left(y_{m_{k}-1}, y_{n_{k}}\right)\right) \rightarrow 1$, implying that $d\left(y_{m_{k}-1}, y_{n_{k}}\right) \rightarrow 0$, a contradiction.

Suppose, e.g., that the subspace $g(X)$ is complete (the proof when $f(X)$ is complete is similar). Then $\left\{y_{n}\right\}$ is a Cauchy sequence, tending to some $y^{*} \in g(X)$, i.e., $y^{*}=g z$ for some $z \in X$. In order to prove that $f z=g z$, suppose that $f z \neq g z$. Then, by Lemma 1 , it follows that $y_{n}$ differs from both $f z$ and $g z$ for $n$ sufficiently large. Hence, we can apply the rectangular inequality to obtain

$$
\begin{aligned}
d(f z, g z) & \leq d\left(f z, f x_{n}\right)+d\left(f x_{n}, f x_{n+1}\right)+d\left(f x_{n+1}, g z\right) \\
& \leq \beta\left(d\left(g z, g x_{n}\right)\right) d\left(g z, g x_{n}\right)+d\left(y_{n}, y_{n+1}\right)+d\left(y_{n+1}, g z\right) \\
& <d\left(g z, g x_{n}\right)+d\left(y_{n}, y_{n+1}\right)+d\left(y_{n+1}, g z\right) \rightarrow 0,
\end{aligned}
$$

as $n \rightarrow \infty$. It follows that $f z=g z$ is a point of coincidence of $f$ and $g$.

In the case when $f$ and $g$ are weakly compatible, a wellknown result implies that $f$ and $g$ have a unique common fixed point.

The following example is inspired by [9, Example 2.4]. Example 2 Let $X=\{a, b, c, \delta, e\} \quad$ and $\quad d: X \times X \rightarrow$ $[0,+\infty)$ be defined by:

$$
\begin{aligned}
& d(x, x)=0 \text { for } \mathrm{x} \in \mathrm{X} \\
& d(x, y)=d(y, x) \text { for } \mathrm{x}, \mathrm{y} \in \mathrm{X} \\
& d(a, b)=3 t \\
& d(a, c)=d(b, c)=t \\
& d(a, \delta)=d(b, \delta)=d(c, \delta)=2 t, \\
& d(a, e)=d(c, e)=t, d(b, e)=d(\delta, e)=2 t,
\end{aligned}
$$

where $0<t<\frac{\log 2}{2}$, i.e., $e^{-2 t}>e^{-\log 2}=\frac{1}{2}$. Then it is easy to check that $(X, d)$ is a g.m.s. which is not a metric space since

$d(a, b)=3 t>2 t=d(a, c)+d(c, b)$.

Consider the following mappings $f, g: X \rightarrow X$. 
$f=\left(\begin{array}{lllll}a & b & c & \delta & e \\ c & c & c & a & c\end{array}\right) \quad g=\left(\begin{array}{lllll}a & b & c & \delta & e \\ a & a & c & \delta & a\end{array}\right)$.

Then $f(X)=\{a, c\} \subset\{a, c, \delta\}=g(X)$. Take the function $\beta \in \mathcal{S}$ defined by $\beta(t)=e^{-t}$ for $t>0$ and $\beta(0) \in[0,1)$. Let us check that $f, g$ satisfy contractive condition (3.1) of Theorem 1. Let $x, y \in X$ with $x \neq y$ and consider the following possible cases:

$1^{\circ} x, y \in\{a, b, c, e\}$. Then $f x=f y=c$ and $d(f x, f y)=0$. Hence, (3.1) trivially holds.

$2^{\circ} x \in\{a, b, e\}, \quad y=\delta$. Then $f x=c, f y=a$ and $d(f x, f y)=t ; g x=a, g y=\delta$ and $d(g x, g y)=2 t$. Hence, $d(f x, f y)=t<e^{-2 t} \cdot 2 t=\beta(2 t) \cdot 2 t=\beta(d(g x, g y)) d(g x, g y)$,

since $1<e^{-2 t} \cdot 2$.

$3^{\circ} x=c, y=\delta$. Then $f x=c, f y=a$ and $d(f x, f y)=t$; $g x=c, g y=\delta$ and $d(g x, g y)=2 t$. Hence, the inequality (3.1) is again satisfied.

All the conditions of Theorem 1 are satisfied and $f$ and $g$ have a unique point of coincidence (which is $c$ ). $c$ is also their unique common fixed point.

Taking $g=i_{X}$, we get the following variant of Geraghty-theorem in generalized metric spaces.

Corollary 1 Let $(X, d)$ be a complete g.m.s. and let $f$ : $X \rightarrow X$ be a self map. If, for some function $\beta \in \mathcal{S}$,

$d(f x, f y) \leq \beta(d(x, y)) d(x, y)$

holds for all $x, y \in X$, then $f$ has a unique fixed point $z$. Moreover, for each $x_{0} \in X$, the corresponding Picard sequence $\left\{x_{n}\right\}$ converges to $z$.

Remark 1 Taking $\beta(t)=\lambda \in(0,1)$ in the previous corollary, we get the Banach contraction principle in generalized metric spaces, proved without the assumption that the space is Hausdorff and/or that the function $d$ is continuous. In a similar way, most of the results from the papers [1, 4, 7-10, 12, 14, 19, 20, 25, 27] can be proved without the assumption of Hausdorffness.

Remark 2 It is easy to see that the result of Theorem 1 remains valid if the inequality (3.1) is replaced by the following one

$d(f x, f y) \leq \beta(M(x, y)) M(x, y)$,

where $M(x, y)=\max \{d(g x, g y), d(g x, f x), d(g y, f y)\}$.

Altering distance functions

Recall (see [34]) that a mapping $\psi:[0,+\infty) \rightarrow[0,+\infty)$ is called an altering distance function if:

(i) $\psi$ is increasing and continuous,

(ii) $\psi(t)=0$ iff $t=0$.
The following theorem is a g.m.s. version of the main result from [34]. Its proof completely follows the lines of proof of Theorem 1 and hence it is omitted.

Theorem 2 Let $(X, d)$ be a g.m.s. and let $f, g: X \rightarrow X$ be two self maps such that $f(X) \subseteq g(X)$, one of these two subsets of $X$ being complete. If, for some altering distance function $\psi$ and some $c \in[0,1)$,

$\psi(d(f x, f y)) \leq c \psi(d(g x, g y))$

holds for all $x, y \in X$, then $f$ and $g$ have a unique point of coincidence. If, moreover, $f$ and $g$ are weakly compatible, then they have a unique common fixed point.

Corollary 2 Let $(X, d)$ be a complete g.m.s. and let $f$ : $X \rightarrow X$ be a self map. If, for some altering distance function $\psi$ and some $c \in[0,1)$,

$\psi(d(f x, f y)) \leq c \psi(d(x, y))$

holds for all $x, y \in X$, then $f$ has a unique fixed point.

Remark 3 It is easy to see that the result of Theorem 2 remains valid if the inequality (3.4) is replaced by the following one

$\psi(d(f x, f y)) \leq c \psi(M(x, y))$,

where $M(x, y)=\max \{d(g x, g y), d(g x, f x), d(g y, f y)\}$.

Admissible functions

In what follows, we will denote by $\Psi$ the family of nondecreasing functions $\psi:[0,+\infty) \rightarrow[0,+\infty)$ such that $\sum_{n=1}^{\infty} \psi^{n}(t)<+\infty$ for each $t>0$, where $\psi^{n}$ is the $n$-th iterate of $\psi$. Note that $\psi(t)<t$ for $\psi \in \Psi$ and $t>0$. Following [35], we adopt the following terminology:

Definition 2 Let $X$ be a nonempty set, $f: X \rightarrow X, \psi \in \Psi$ and $\alpha: X \times X \rightarrow[0,+\infty)$.

1. $f$ is said to be $\alpha$-admissible if

$$
x, y \in X, \quad \alpha(x, y) \geq 1 \Longrightarrow \alpha(f x, f y) \geq 1 \text {. }
$$

2. If $(X, d)$ is a metric space, then $f$ is called $\alpha-\psi$ contractive if

$$
\alpha(x, y) d(f x, f y) \leq \psi(d(x, y))
$$

for all $x, y \in X$.

Samet et al. in [35], as well as several other authors proved various fixed point theorems for $\alpha$-admissible mappings. We will prove one such result in the context of generalized metric spaces (as a modification of [35, Theorem 2.1, Theorem 2.2]). 
Theorem 3 Let $(X, d)$ be a complete g.m.s. and $f: X \rightarrow$ $X$ be an $\alpha$ - $\psi$-contractive mapping (for some $\alpha$ and $\psi \in \Psi$ ) satisfying the following conditions:

(1) $f$ is $\alpha$-admissible;

(2) there exists $x_{0} \in X$ such that $\alpha\left(x_{0}, f x_{0}\right) \geq 1$ and $\alpha\left(x_{0}, f^{2} x_{0}\right) \geq 1$

(3) $f$ is continuous, or

(3') if $\left\{x_{n}\right\}$ is a sequence in $X$ such that $\alpha\left(x_{n}, x_{n+1}\right) \geq 1$ for all $n$ and $x_{n} \rightarrow x \in X$ as $n \rightarrow \infty$, then $\alpha\left(x_{n}, x\right) \geq 1$ for all $n$.

Then $f$ has a fixed point.

Proof Starting from $x_{0}$ given in (2), construct the sequence $\left\{x_{n}\right\}$ as $x_{n+1}=f x_{n}, n \in \mathbb{N}$. If $x_{n}=x_{n+1}$ for some $n \in \mathbb{N} \cup\{0\}$, then $x^{*}=x_{n}$ is a fixed point of $f$. Assume further that $x_{n} \neq x_{n+1}$ for each $n \in \mathbb{N} \cup\{0\}$.

Since $f$ is $\alpha$-admissible, it follows from (2) that $\alpha\left(x_{1}, x_{2}\right)=\alpha\left(f x_{0}, f x_{1}\right) \geq 1 \quad$ and $\quad \alpha\left(\mathrm{x}_{1}, \mathrm{x}_{3}\right)=\alpha\left(\mathrm{fx}_{0}, \mathrm{fx}_{2}\right) \geq 1$.

By induction, we get

$\alpha\left(x_{n}, x_{n+1}\right) \geq 1 \quad$ and $\quad \alpha\left(\mathrm{x}_{\mathrm{n}}, \mathrm{x}_{\mathrm{n}+2}\right) \geq 1 \quad$ foralln $\in \mathbb{N}$.

Applying the inequality (3.5) and using the previous relations, we get

$d\left(x_{n}, x_{n+1}\right)=d\left(f x_{n-1}, f x_{n}\right) \leq \alpha\left(x_{n-1}, x_{n}\right)$

$d\left(f x_{n-1}, f x_{n}\right) \leq \psi\left(d\left(x_{n-1}, x_{n}\right)\right)$,

and by induction,

$d\left(x_{n}, x_{n+1}\right) \leq \psi^{n}\left(d\left(x_{0}, x_{1}\right)\right)$ forn $\in \mathbb{N}$.

In a similar way, we obtain

$d\left(x_{n}, x_{n+2}\right) \leq \psi^{n}\left(d\left(x_{0}, x_{2}\right)\right)$ forn $\in \mathbb{N}$.

Using the properties of function $\psi \in \Psi$, we get that both sequences $\left\{d\left(x_{n}, x_{n+1}\right)\right\}$ and $\left\{d\left(x_{n}, x_{n+2}\right)\right\}$ are nonincreasing and tend to 0 as $n \rightarrow \infty$. Suppose that $x_{n}=x_{m}$ for some $m, n \in \mathbb{N}, m<n$. Then

$d\left(x_{m}, x_{m+1}\right)=d\left(x_{n}, x_{n+1}\right) \leq \psi^{n-m}\left(d\left(x_{m}, x_{m+1}\right)\right)<d\left(x_{m}, x_{m+1}\right)$,

a contradiction. Hence, all elements of the Picard sequence $\left\{x_{n}\right\}$ are distinct.

In order to prove that $\left\{x_{n}\right\}$ is a Cauchy sequence in $(X, d)$, we consider the distance $d\left(x_{n}, x_{n+p}\right)$ in the cases $p=2 m+1$ and $p=2 m$. In the first case, using the rectangular inequality and (3.6), we get that

$$
\begin{aligned}
d\left(x_{n}, x_{n+2 m+1}\right) \leq & d\left(x_{n}, x_{n+1}\right)+d\left(x_{n+1}, x_{n+2}\right)+d\left(x_{n+2}, x_{n+2 m+1}\right) \leq \ldots \\
\leq & d\left(x_{n}, x_{n+1}\right)+d\left(x_{n+1}, x_{n+2}\right)+\ldots+d\left(x_{n+2 m}, x_{n+2 m+1}\right) \\
\leq & \psi^{n}\left(d\left(x_{0}, x_{1}\right)\right)+\psi^{n+1}\left(d\left(x_{0}, x_{1}\right)\right)+\ldots \\
& +\psi^{n+2 m}\left(d\left(x_{0}, x_{1}\right)\right) .
\end{aligned}
$$

The last expression tends to 0 as $n \rightarrow \infty$, since the series $\sum_{n=1}^{\infty} \psi^{n}\left(d\left(x_{0}, x_{1}\right)\right)$ converges, by the properties of function $\psi \in \Psi$.

In the case $p=2 m$, using (3.7) we obtain in a similar way that

$$
\begin{aligned}
d\left(x_{n}, x_{n+2 m}\right) \leq & d\left(x_{n}, x_{n+2}\right)+d\left(x_{n+2}, x_{n+3}\right)+\ldots \\
+ & d\left(x_{n+2 m-1}, x_{n+2 m}\right) \\
& \leq \psi^{n}\left(d\left(x_{0}, x_{2}\right)\right)+\psi^{n+2}\left(d\left(x_{0}, x_{1}\right)\right)+\ldots \\
+ & \psi^{n+2 m-1}\left(d\left(x_{0}, x_{1}\right)\right) .
\end{aligned}
$$

Again, by the properties of function $\psi$, it follows that $d\left(x_{n}, x_{n+2 m}\right) \rightarrow$ as $n \rightarrow \infty$. Hence, $\left\{x_{n}\right\}$ is a Cauchy sequence that converges to some $x^{*}$ in the complete g.m.s. $(X, d)$.

In the case (3) when the function $f$ is continuous, it immediately follows that $f x^{*}=x^{*}$, since a Cauchy sequence with distinct elements in $(X, d)$ cannot have two limits, by Lemma 1.

Assume now that condition $\left(3^{\prime}\right)$ holds. Using that $x_{n}$ differs from $x^{*}$ and $f x^{*}$ for $n$ sufficiently large, we get that for such $n$,

$d\left(x^{*}, f x^{*}\right) \leq d\left(x^{*}, x_{n}\right)+d\left(x_{n}, x_{n+1}\right)+d\left(f x_{n}, f x^{*}\right)$.

The first two terms on the right-hand side tend to 0 as $n \rightarrow \infty$, and for the third one we have that

$$
\begin{aligned}
& d\left(f x_{n}, f x^{*}\right) \leq \alpha\left(x_{n}, x^{*}\right) d\left(f x_{n}, f x^{*}\right) \\
& \leq \psi\left(d\left(x_{n}, x^{*}\right)\right)<d\left(x_{n}, x^{*}\right) \rightarrow 0,
\end{aligned}
$$

as $n \rightarrow \infty$. Hence, $d\left(x^{*}, f x^{*}\right)=0$, i.e., $x^{*}$ is a fixed point of $f$.

The following example is inspired by [28, Example 2] and [36, Example 2.7].

Example 3 Let $X=\left\{\frac{1}{n}: n \in \mathbb{N}\right\} \cup\{0\}$ and define $d: X \times$ $X \rightarrow[0,+\infty)$ by

$d(x, y)= \begin{cases}0, & x=y, \\ \frac{1}{n}, & \{x, y\}=\left\{0, \frac{1}{n}\right\}, \\ 1, & x \neq y, x, y \in X \backslash\{0\} .\end{cases}$

Then it is easy to see that $(X, d)$ is a complete g.m.s. which is not a metric space.

Consider now $f: X \rightarrow X$ given as

$f x= \begin{cases}\frac{1}{4}, & x \in X \backslash\{1\}, \\ 0, & x=1,\end{cases}$

and $\alpha: X \times X \rightarrow[0,+\infty)$ given as 
$\alpha(x, y)= \begin{cases}1, & (x, y) \in\left(\left[0, \frac{1}{4}\right] \times\left[\frac{1}{4}, 1\right]\right) \cup\left(\left[\frac{1}{4}, 1\right] \times\left[0, \frac{1}{4}\right]\right), \\ 0, & \text { otherwise }\end{cases}$

Finally, take $\psi \in \Psi$ defined by $\psi(t)=\frac{t}{2}, t \in[0,+\infty)$. We will prove that:

(a) $f$ is an $\alpha-\psi$-contractive mapping;

(b) $f$ is $\alpha$-admissible;

(c) there exists $x_{0} \in X$ such that $\alpha\left(x_{0}, f x_{0}\right) \geq 1$ and $\alpha\left(x_{0}, f^{2} x_{0}\right) \geq 1$;

(d) if $\left\{x_{n}\right\}$ is a sequence in $X$ such that $\alpha\left(x_{n}, x_{n+1}\right) \geq 1$ for all $n$ and $x_{n} \rightarrow x \in X$ as $n \rightarrow \infty$, then $\alpha\left(x_{n}, x\right) \geq 1$ for all $n$.

\section{Proof}

(a) The only nontrivial case to check is when $x \in\left[0, \frac{1}{4}\right]$ and $y=1$ (or vice versa). Then

$$
\alpha(x, y) d(f x, f y)=d\left(\frac{1}{4}, 0\right)=\frac{1}{4}<\frac{1}{2} \cdot 1=\psi(d(x, y)) .
$$

(b) It was proved in [36, Example 2.7].

(c) For $x_{0}=0, \quad$ we have $\alpha\left(x_{0}, f x_{0}\right)=\alpha\left(x_{0}, f^{2} x_{0}\right)=\alpha\left(0, \frac{1}{4}\right)=1$.

(d) Let $\left\{x_{n}\right\}$ be a sequence in $X$ such that $\alpha\left(x_{n}, x_{n+1}\right) \geq 1$ for all $n$ and $x_{n} \rightarrow x$ as $n \rightarrow \infty$. From definition of $\alpha$, it follows that

$\left(x_{n}, x_{n+1}\right) \in\left(\left[0, \frac{1}{4}\right] \times\left[\frac{1}{4}, 1\right]\right) \cup\left(\left[\frac{1}{4}, 1\right] \times\left[0, \frac{1}{4}\right]\right)$.

Then, the only possibility is that $x=\frac{1}{4}$. Thus we have $\alpha\left(x_{n}, x\right) \geq 1$ for all $n$. Hence, all the conditions of Theorem 3 are satisfied, and $f$ has a fixed point (which is $x^{*}=\frac{1}{4}$ ).

\section{Cone rectangular metric spaces}

Cone metric spaces were defined by L. G. Huang and X. Zhang in [37]. Following this paper, a huge number of articles appeared where various fixed point results in such spaces were proved. However, later it became clear that a lot of these results can be reduced to their standard metric counterparts using various methods. These include, among others, the so-called scalarization method [38] and the method of Minkowski functional [39].

Generalized cone metric spaces and fixed point results in them were treated in $[6,21,22,31]$. We will show that some of these results can be deduced from the respective g.m.s. results using Minkowski functionals, similarly as in [39].
Definition 3 Let $(E,\|\cdot\|)$ be a real Banach space with $\theta$ as the zero element and a solid cone $P$ with the respective order $\preceq$. Let $X$ be a nonempty set and $d: X \times X \rightarrow E$ satisfy the following

1. $\theta \preceq d(x, y)$ for all $x, y \in X$ and $d(x, y)=\theta$ if and only if $x=y$;

2. $d(x, y)=d(y, x)$ for all $x, y \in X$;

3. $d(x, y) \preceq d(x, u)+d(u, v)+d(v, y)$ for all $x, y \in X$ and for all distinct points $u, v$, both distinct from $x$ and $y$.

Then $d$ is called a cone rectangular metric on $X$ and $(X, d)$ is called a cone rectangular metric space (or a cone g.m.s.).

Recall also the following (see, e.g., [39]).

If $V$ is an absolutely convex and absorbing subset of $E$, its Minkowski functional $q_{V}$ is defined by

$E \ni x \mapsto q_{V}(x)=\inf \{\lambda>0: x \in \lambda V\}$.

It is a semi-norm on $E$. If $V$ is an absolutely convex neighborhood of $\theta$ in $E$, then $q_{V}$ is continuous and

$\left\{x \in E: q_{V}(x)<1\right\}=\operatorname{int} V \subset V \subset \bar{V}=\left\{x \in E: q_{V}(x) \leq 1\right\}$.

Let $e \in$ int $P$. Then $[-e, e]=(P-e) \cap(e-P)=\{z \in E$ : $-e \preceq z \preceq e\}$ is an absolutely convex neighborhood of $\theta$; its Minkowski functional $q_{[-e, e]}$ will be denoted by $q_{e}$.

The following theorem can be proved in a very similar way as [39, Theorem 3.2].

Theorem 4 Let $(X, d)$ be a cone g.m.s. over a solid cone $P$ and let $e \in \operatorname{int} P$. Let $q_{e}$ be the corresponding Minkowski functional of $[-e, e]$. Then $d_{q}=q_{e} \circ d$ is a (real-valued) rectangular metric on $X$. Moreover,

1. For a sequence $\left\{x_{n}\right\}$ in $X, \lim _{n \rightarrow \infty} x_{n}=x$ in $(X, d)$ if and only if $\lim _{n \rightarrow \infty} x_{n}=x$ in $\left(X, d_{q}\right)$.

2. $\left\{x_{n}\right\}$ is a d-Cauchy sequence if and only if it is a $d_{q^{-}}$ Cauchy sequence.

3. $(X, d)$ is complete if and only if $\left(X, d_{q}\right)$ is complete.

As a consequence, most of the results from the papers $[6,21,22,31]$ can be proved by reducing them to respective known results in (standard) g.m.s. As a sample, we will state the result for the quasicontraction (in the sense of Cirić [40]). It is clear that the result will remain valid for several other contractive conditions listed in the well-known Rhoades's paper [41].

Recall the following recent result proved in [28, Theorem 6]:

Theorem 5 [28] Let $(X, \rho)$ be a complete partial rectangular metric space and $f: X \rightarrow X$ be a quasicontraction, i.e., there exists $\lambda \in[0,1)$ such that

$\rho(f x, f y) \leq \lambda \max \{\rho(x, y), \rho(x, f x), \rho(y, f y), \rho(x, f y), \rho(y, f x)\}$ 
for all $x, y \in X$. Then $f$ has a unique fixed point $x^{*} \in X$ (and $\rho\left(x^{*}, x^{*}\right)=0$ ).

Since each g.m.s. is also a partial rectangular metric space, the previous theorem remains valid in generalized metric spaces. Now, applying Theorem 4, we get the following.

Corollary 3 Let $(X, d)$ be a complete cone g.m.s. and let $f: X \rightarrow X$ has the property that for some $\lambda \in[0,1)$ and for all $x, y \in X$ there exists

$u(x, y) \in\{d(x, y), d(x, f x), d(y, f y), d(x, f y), d(y, f x)\}$

such that $d(f x, f y) \preceq \lambda u(x, y)$. Then $f$ has a unique fixed point in $X$.

Remark 4 As a consequence, we get that several other fixed point results (as, e.g., Kannan's, Chatterjea's, Zamfirrescu's and others, listed in [41]) can be proved in g.m.s. without using the assumption of Hausdorffness.

Fixed point and common fixed point results can be proved in ordered g.m.s., as well. Since some of them were already obtained in $[21,22]$, we will not treat them here.

We conclude by citing some additional recent references concerned with extensions of the mentioned results to some other types of spaces [42-45].

Acknowledgments The authors are indebted to the referees of this paper who helped us to improve its presentation. The authors are thankful to the Ministry of Education, Science and Technological Development of Serbia.

Conflict of interest The authors declare that they have no competing interests.

Open Access This article is distributed under the terms of the Creative Commons Attribution License which permits any use, distribution, and reproduction in any medium, provided the original author(s) and the source are credited.

\section{References}

1. Branciari, A.: A fixed point theorem of Banach-Caccioppoli type on a class of generalized metric spaces. Publ. Math. Debrecen 57, 31-37 (2000)

2. Ahmad, J., Arshad, M., Vetro, C.: On a theorem of Khan in a generalized metric space. Intern. J. Anal. 2013, 6, Art. ID 852727 (2013)

3. Arshad, M., Ahmad, J., Karapinar, E.: Some common fixed point results in rectangular metric spaces. Int. J. Math. Anal. 2013, 7, Art. ID 307234 (2013)

4. Aydi, H., Karapinar, E., Lakzian, H.: Fixed point results on a class of generalized metric spaces. Math. Sci. 6, 46 (2012)

5. Azam, A., Arshad, M.: Kannan fixed point theorem on generalized metric spaces. J. Nonlinear Sci. Appl. 1(1), 45-48 (2008)

6. Azam, A., Arshad, M., Beg, I.: Banach contraction principle on cone rectangular metric spaces. Appl. Anal. Discrete Math. 3, 236-241 (2009)
7. Bilgili, N., Karapinar, E., Turkoglu, D.: A note on common fixed points for $(\psi, \alpha, \beta)$-weakly contractive mappings in generalized metric spaces. Fixed Point Theory Appl. 2013, 287 (2013)

8. Cakić, N.: Coincidence and common fixed point theorems for $(\psi, \varphi)$ weakly contrative mappings in generalized metric spaces. Filomat 27(8), 1415-1423 (2013)

9. Chen, Ch.-M.: Common fixed-point theorems in complete generalized metric spaces. J. Appl. Math. 2012, 14, Art. ID 945915 (2012)

10. Chen, Ch.-M., Sun, W.Y.: Periodic points and fixed points for the weaker $(\phi, \varphi)$-contractive mappings in complete generalized metric spaces. J. Appl. Math. 2012, 7, Art. ID 856974 (2012)

11. Das, P., Dey, L.K.: A fixed point theorem in generalized metric spaces. Soochow J. Math. 33(1), 33-39 (2007)

12. Di Bari, C., Vetro, P.: Common fixed points in generalized metric spaces. Appl. Math. Comput. 218, 7322-7325 (2012)

13. Flora, A., Bellour, A., Al-Bsoul, A.: Some results in fixed point theory concerning generalized metric spaces. Mat. Vesnik 61(3), 203-208 (2009)

14. Isik, H., Turkoglu, D.: Common fixed points for $(\psi, \alpha, \beta)$-weakly contractive mappings in generalized metric spaces. Fixed Point Theory Appl. 2013, 131 (2013)

15. Kikina, L., Kikina, K.: Fixed points on two generalized metric spaces. Int. J. Math. Anal. 5(30), 1459-1467 (2011)

16. Kikina, L., Kikina, K., Gjino, K.: A new fixed point theorem on generalized quasimetric spaces. ISRN Math. Anal. 2012, 9, Art. ID 457846 (2012)

17. Kirk, W.A., Shahzad, N.: Generalized metrics and Caristi's theorem. Fixed Point Theory Appl. 2013, 129 (2013)

18. Kumar, M., Kumar, P., Kumar, S.: Some common fixed point theorems in generalized metric spaces. J. Math. 2013, 7, Art. ID 719324 (2013)

19. Lahiri, B.K., Das, P.: Fixed point of a Ljubomir Ćirić's quasicontraction mapping in generalized metric spaces. Publ. Math. Debr. 61(3-4), 589-594 (2002)

20. Lakzian, H., Samet, B.: Fixed point for $(\psi, \varphi)$-weakly contractive mappings in generalized metric spaces. Appl. Math. Lett. 25(5), 902-906 (2011)

21. Malhotra, S.K., Sharma, J.B., Shukla, S.: g-weak contraction in ordered cone rectangular metric spaces. Sci. World J. 2013, 7, Art. ID 810732 (2013)

22. Malhotra, S.K., Shukla, S., Sen, R.: Some fixed point theorems for ordered Reich type contractions in cone rectangular metric spaces. Acta Math. Univ. Comen. 82, 165-175 (2013)

23. Mihet, D.: On Kannan fixed point principle in generalized metric spaces. J. Nonlinear Sci. Appl. 2(2), 92-96 (2009)

24. Moradi, S., Alimohammadi, D.: New extensions of Kannan fixedpoint theorem on complete metric and generalized metric spaces. Int. J. Math. Anal. 5(47), 2313-2320 (2011)

25. Samet, B.: A fixed point theorem in a generalized metric space for mappings satisfying a contractive condition of integral type. Int. J. Math. Anal. 3(26), 1265-1271 (2009)

26. Samet, B.: Discussion on "A fixed point theorem of BanachCaccioppoli type on a class of generalized metric spaces" by A. Branciari. Publ. Math. Debr. 76, 493-494 (2010)

27. Sarma, I.R., Rao, J.M., Rao, S.S.: Contractions over generalized metric spaces. J. Nonlinear Sci. Appl. 2(3), 180-182 (2009)

28. Shukla, S.: Partial rectangular metric spaces and fixed point theorems. Sci. World J. 2014, 7, Art. ID 756298 (2014)

29. Turinici, M.: Functional contractions in local Branciari metric spaces. arXiv:1208.4610v1 [math.GN]. 22 Aug 2012.

30. Kadelburg, Z., Radenović, S.: On generalized metric spaces: a survey. TWMS J. Pure Appl. Math. 5(1), 3-13 (2014)

31. Jleli, M., Samet, B.: The Kannan fixed point theorem in a cone rectangular metric space. J. Nonlinear Sci. Appl. 2, 161-167 (2009) 
32. Radenović, S., Kadelburg, Z., Jandrlić, D., Jandrlić, A.: Some results on weak contraction maps. Bull. Iran. Math. Soc. 38(3), 625-645 (2012)

33. Geraghty, M.: On contractive mappings. Proc. Am. Math. Soc. 40, 604-608 (1973)

34. Khan, M.S., Swaleh, M., Sessa, S.: Fixed point theorems by altering distances between the points. Bull. Aust. Math. Soc. 30(1), 1-9 (1984)

35. Samet, B., Vetro, C., Vetro, P.: Fixed point theorems for $\alpha-\psi-$ contractive type mappings. Nonlinear Anal. TMA 75, 2154-2165 (2012)

36. Karapinar, E., Samet, B.: Generalized $\alpha-\psi$ contractive type mappings and related fixed point theorems with applications. Abstract Appl. Anal. 2012, 17, Art. ID 793486 (2012)

37. Huang, L.G., Zhang, X.: Cone metric spaces and fixed point theorems of contractive mappings. J. Math. Anal. Appl. 332(2), 1468-1476 (2007)

38. Du, W.-S.: A note on cone metric fixed point theory and its equivalence. Nonlinear Anal. 72, 2259-2261 (2010)
39. Kadelburg, Z., Radenović, S., Rakočević, V.: A note on the equivalence of some metric and cone metric fixed point results. Appl. Math. Lett. 24, 370-374 (2011)

40. Ćirić, L.B.: A generalization of Banach's contraction principle. Proc. Am. Math. Soc. 45, 267-273 (1974)

41. Rhoades, B.E.: A comparison of various definitions of contractive mappings. Trans. Am. Math. Soc. 336, 257-290 (1977)

42. Mustafa, Z., Roshan, J.R., Parvaneh, V., Kadelburg, Z.: Common fixed point results in ordered partial b-metric spaces. J. Inequal. Appl. 2013, 562 (2013)

43. Hussain, N., Roshan, J.R., Parvaneh, V., Latif, A.: A unification of $G$-metric, partial metric and $b$-metric spaces. Abstract Appl. Anal. 2014, 14, Art. ID 180698 (2014)

44. Hussain, N., Parvaneh, V., Roshan, J.R.: Fixed point results for $G$ - $\alpha$-contractive maps with application to boundary value problems. Sci. World J. 2014, 14, Art. ID 585964 (2014)

45. Hussain, N., Roshan, J.R., Parvaneh, V., Kadelburg, Z.: Fixed points of contractive mappings in $b$-metric-like spaces. Sci. World J. 2014, 15, Art. ID 471827 (2014) 